\title{
Prevalence and factors associated to contamination from porcine epidemic diarrhea virus during the transportation of pigs to slaughterhouses in Colombia
}

\section{Maria del Pilar Pineda Ortiz}

Universidad Del Rosario https://orcid.org/0000-0001-9752-3438

Johanna Paola Corrales Morales

Universidad Del Rosario

Gilma Hernández Herrera

Universidad de Antioquia

Carlos Enrique Trillos Pena ( $\square$ carlos.trillos@urosario.edu.co)

Universidad Del Rosario https://orcid.org/0000-0003-0422-0011

Diana Corina Zambrano Moreno

Asociación Colombiana de Porcicultores

\section{Research article}

Keywords: coronavirus, epidemiology, PEDV, prevalence, swine

Posted Date: December 4th, 2020

DOI: https://doi.org/10.21203/rs.2.14514/v2

License: (c) (1) This work is licensed under a Creative Commons Attribution 4.0 International License.

Read Full License 


\section{Abstract}

Porcine epidemic diarrhea virus (PEDV) causes acute diarrhea, dehydration, and high mortality in newborn piglets and has caused high economic impact in the swine industry in the United States and Asia. Until March 2014, PED was an exotic disease in Colombia. This study was carried out at the beginning of the spread of PEDV in the country, and its main objective was to determine the prevalence and factors associated to the contamination of PEDV in the transportation of pigs to the slaughterhouses in Colombia through environmental samples analyzed by RT-PCR. 518 pig trucks in the 32 main slaughterhouses, were sampled and the drivers of the trucks fulfilled a questionnaire. The prevalence of PEDV at the entrance of the slaughterhouses was $71.8 \%$ (Cl 95\%: 70.8-72.8) versus $70.5 \%$ (CI 95\%: 69.571.5) at the slaughterhouse exit, and there was no evidence of significant differences between both rates. (McNemar value p: 0.375 ). The factors that increased the possibility of truck contamination were: vehicles that visit national slaughterhouses (OR 15.9 95\% Cl: 4.9-51.85) and that visit national -export type (OR 9.0 95\% Cl: 2.20-36.91), trucks with mobility in area of greatest slaughter (OR $9.0595 \%$ Cl: 2.927.63), the non-exclusive use of vehicles to transport pigs (OR $3.7595 \% \mathrm{Cl}: 1.55-9.08$ ) and visit animal feed mills (OR $13.595 \% \mathrm{Cl}: 4.1-44.12$ ). The factors identified that reduce the possibility of contamination were cleanliness of the body truck (OR $0.08995 \% \mathrm{Cl}: 0.03-0.23$ ) and the cabin (OR 0.16 95\%Cl: 0.08-0.31), use of disinfectant (OR $0.3295 \% \mathrm{Cl}: 0.16-0.62$ ), pressurized water (OR $0.3895 \%$ $\mathrm{Cl}: 0.15-0.95$ ), and back pump (OR $0.1795 \% \mathrm{Cl}: 0.08-0.35$ ) and the exclusive use of the vehicle for pig transportation (OR 0.36 95\% Cl: 0.19-0.70). The results showed that the high grade of mobilization of the trucks to points of concentration, failures in biosecurity and virus survival characteristics, enabled the spread of PEDV, turning it into an endemic disease in Colombia; however, the measures implemented by the farmers mitigated the impact of the disease. We evidenced the need of standardizing and regulating biosecurity protocols for slaughterhouses, pig transportation and farms.

\section{Background}

Porcine epidemic diarrhea (PED) is a common type of viral enteritis in pigs, caused by an RNA type virus that belongs to the Niroviridales order, Coronaviridae family, Coronavirinae subfamily and Alphacoronovirus genus known as PED virus (PEDV) $(1,2)$.Diarrhea is the main clinical sign associated with this disease, with other signs such as vomiting, anorexia, dehydration, and weight loss $(3,4)$.

PEDV can infect pigs at any age, from neonates to sows or gilts but the severity in pigs varies according to age and immunological status (4-7). Incubation period is of approximately $1-4$ days $(3,8)$ and the clinical signs can be observed after 22-36 hours. The pathogenesis is related to the age of pigs at the time of infection, virus strain virulence, inoculation routes, and doses. (7). PEDV survive in fresh feces up to 7 days in temperatures between $40^{\circ} \mathrm{C}$ to $60^{\circ} \mathrm{C}$ with $30 \%$ to $70 \%$ relative humidity, they also survive in liquid fertilizer during 14 days at room temperature, even with low doses of infection ( $10^{\llbracket 2}$ to

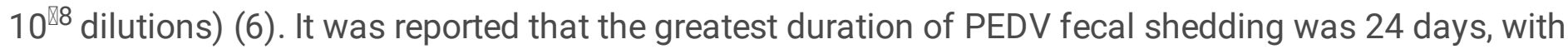
intermittent shedding up to 42 days after inoculation (4). 
PEDV is commonly transmitted from one animal to another through the fecal - oral pathway. It can also be introduced in susceptible farms through pigs, manure, fomites (equipment, boots, clothes, supplies, material that can transport manure) and staff (hands), contaminated transportation, (9-11) feed (9) and feed containing spray dried porcine plasma (12). Also be an important source of transmission of the virus since factors such as storage temperature, composition and porosity of the materials can affect the survival of the PEDV and hence virus transmission, which survives better in the presence of organic material $(13,14)$. PEVD survival in glass, stainless steel, metal, polyethylene foam and plastic can last between 10 to 20 days at $4^{\circ} \mathrm{C}$, being even greater in rubber and anti-fluid overalls; whereas at room temperature, the capacity for survival was reduced to 2 days for all materials $(13,15)$. PEDV circulate in farms when newborn piglets can't obtain enough levels of maternal immunity, which causes the infection in susceptible animals and the reappearance of epidemic outbreaks (8).

PED was an exotic disease in the American continent until 2013, when it appeared in the United States, causing the death of 7 million swine, the majority of which were piglets $(16,17)$. Then, outbreaks emerged in Mexico, Peru, Canada, the Dominican Republic and Ecuador. In Colombia, the first report of PED was in March 2014. Cases of PED in Colombia between 2014 and 2015 decreased productivity in the porcine sector due to the increase in production costs and the slow growth of the pigs, making the control and prevention of this disease a important concern for farmers.

At the beginning of the outbreaks, there was no knowledge on the role of slaughterhouses and the transportation of pigs as sources of contamination for spread of PEDV since the process had not been studied enough, so knowledge in this field will allow changes in biosecurity practices and pig transportation, focusing mainly on slaughterhouses; and the management of pigs on trucks could help prevent and control spread of PEDV through this means. This study's main objective was to determine the prevalence of contamination by PEDV in trucks that transport pigs to slaughterhouses and associated transportation practices.

\section{Results}

\section{Prevalence of trucks contaminated with PEDV}

The prevalence of trucks contaminated upon slaughterhouse entrance was $71.8 \%$ and $20.12 \%$ of the trucks were suspicious; while the prevalence of trucks contaminated with PEDV at the exit of the slaughterhouse was $70.5 \%$ and $19.5 \%$ of the truck were suspicious. (Table 1 )

Table 1. Proportion of trucks contaminated by PEDV at slaughterhouse

\begin{tabular}{cccccc}
\hline $\begin{array}{c}\text { Real time } \\
\text { PCR }\end{array}$ & \multicolumn{2}{c}{ On entry to the slaughterhouse } & \multicolumn{2}{c}{ On exit of the slaughterhouse } \\
\cline { 2 - 6 } & & $\mathrm{n}(\%)$ & CI $95 \%$ & $\mathrm{n}(\%)$ & CI $95 \%$ \\
\hline RT PCR Result & $(-)$ & $42(8.1)$ & $7.1-9.1$ & $52(10)$ & $9-11$. \\
\cline { 2 - 6 } & $(+)$ & $372(71.8)$ & $70.8-72.8$ & $365(70.5)$ & $69.5-71.5$ \\
\cline { 2 - 6 } & $(+/-)$ & $104(20.1)$ & $19.1-21.1$ & $101(19.5)$ & $18.5-20.5$ \\
\cline { 2 - 6 } & Total & 518 & 518 \\
\hline
\end{tabular}


(+/[) suspicious

\section{Characterization of practices related to transportation of pigs:}

Fifty nine percent of the surveys were carried out in national slaughterhouses, followed by $30 \%$ and $10 \%$ in exportation and local slaughterhouses respectively. Additionally, $88.6 \%$ of the trucks were sampled in plants located in the area of greater sacrifice (area where the majority of slaughterhouses are located). (Figure 1).

With regards to practices used in slaughterhouses, $57 \%$ (299) of the truck were sprayed with disinfectant at the slaughterhouse entrance; in 67.8\% (351 trucks) disinfection was done with back pump or spraying equipment, whereas $25.1 \%$ (130 trucks) did not undergo any disinfection process. In addition, beds (straw or wood shavings) were only gathered in $44.8 \%$ (232) of the trucks and in $59.5 \%$ (308) these were not disinfected. (Supplementary material Table)

Fig. 1 Slaughterhouse distribution according to type of slaughterhouse and area of sacrifice.

Source: Author's design

\section{Mobilization practices:}

$68.1 \%$ of the trucks visited a destination or place (only farm or slaughterhouse); $96.7 \%$ (501 trucks) do not visit the animal fair, while $48.8 \%$ (253 trucks) visited feed mills. Additionally, 37.3\% of the trucks were used exclusively for pig transportation and $62.2 \%$ to transport pigs and other products. When evaluating the number of departments visited by the trucks, we found that $83.4 \%$ (432 trucks) moved within the same department, while $54.8 \%$ (284) of the trucks transport animals or products once a week.

\section{Truck cleaning practices:}

The $93.8 \%$ (486) of the cases cleaned the truck after each trip and the $49.2 \%$ ( 255 trucks) cleaned daily. Specifically, in $95.8 \%$ (496 trucks) they clean the truck's body, $92.7 \%$ clean the tires (480 trucks) and $80.5 \%$ (417 trucks) clean the cabin. The cleaning elements that were most used on the trucks were: water (96.9\%), soap (47.7\%) and disinfectant (77.4\%). The removal of organic matter was reported for $93.8 \%$ (486) of the trucks.

\section{Transportation practices:}

With regards to the use of supplies and equipment during transportation, 53.9\% (279 drivers) reported not using any, $66.4 \%$ (344 drivers) did not use overalls, 53.9\% (279 drivers) do not use boots, and $88 \%$ (456 drivers) do not use gloves. In addition, $81.7 \%$ (423 drivers) expressed that the step off the vehicle when they arrive at the farms or slaughterhouses.

Practices at the farms in preparation for transportation: 
Washing and disinfection of trucks at the farm were done in 89\% (461 trucks), where the main disinfection systems used were the back pump 80.9\% (419 trucks) and the disinfection arch 10.2\% (53 trucks). Whereas, to enter the farm, 79.3\% (411 drivers) did not shower, and 68.9\% (357 drivers) did not use any protective element. As far as supply of protective elements and equipment to the drivers, $49.4 \%$ (256 drivers) did not receive any, and 60.2\% (312 drivers) and 52.3\% (271 drivers) did not receive overalls and boots respectively. Additionally, 58.9\% (305 trucks) are for the farm's exclusive use.

Factors associated to the presence of PEDV and practices in transportation to slaughterhouses:

Washing practices vs. RT - PCR Results: $98 \%$ (391) of the trucks did not have any changes in the RT-PCR at the entrance or exit of the slaughterhouse, and only $1 \%$ (4) of the trucks that were positive before the washing had a negative result after this process (McNemar $p$ value: 0.375 ). Therefore, there is no evidence that disinfection in the slaughterhouses is associated with a modification of the PCR result.

Table 2 shows the main factors associated to contamination with PEDV such as: the type of slaughterhouse - national or national - export slaughterhouse, the washing system, the non-exclusive use of vehicles for the transportation of pigs, visits to animal feed mills, drivers that getting off the trucks and do not use personal protective equipment. The factors identified that reduce the possibility of contamination were cleanliness of the body truck and the cabin, use of disinfectant, pressurized, and back pump and the exclusive use of the vehicle for pig transportation.

Table 2 Factors associated to contamination by PEDV

Due to technical limitations, full-text HTML conversion of Table 2 could not be completed. However, the table can be downloaded and accessed in the Supplementary Files.

Association between RT PCR results and practices related to transportation:

Two models were applied to associate PEDV with biosecurity measures in transportation. The variables used were adjusted and provided the best explanation for each model. The first model contained independent variables related to the slaughterhouses such as: type of plant, zone where the slaughterhouse was located, and vehicle use, where reference categories were; local plant, zone of lower sacrifice and transportation of only pigs respectively. The second model contained independent variables related to biosecurity practices in porcine mobilization such as they type of plant, visits to animal fairs, and visits to feed mills, where the reference categories for each one were: local plant, not visiting fairs, and not visiting animal feed mills, respectively.

P-values were obtained for the goodness of fit of the models, determined by the Hosmer-Lemeshow test, of 0.240 and 0.950 , which indicates a good adjustment of the logistic model in both cases. (Tables 3 and $4)$.

The factors that increased the possibility of a truck being positive for PEDV when entering a slaughterhouse were: the national type (OR 15.9, Cl 95\%: 4.9-51.85) and the export type (OR 9.0, $\mathrm{Cl} 95 \%$ : 
2.20-36.91), the highest slaughter area (area where the majority of slaughterhouses are located) (OR 9.05, $\mathrm{Cl} 95 \%$ : 2.96-27.63) and the use of vehicles for transportation of pigs and other products (OR $3.75, \mathrm{Cl}$ $95 \%: 1.55-9.08)$ instead of only pigs. Table 3.

Table 3 Model 1: PEDV RT-PCR versus slaughterhouse variables

\begin{tabular}{|c|c|c|c|c|}
\hline Variable & $\begin{array}{l}\text { Adjusted } \\
\text { OR }\end{array}$ & CI 95\% & $\begin{array}{l}\text { for the adjusted } \\
\text { OR }\end{array}$ & p value \\
\hline Slaughterhouse type & & & & $<0.001$ \\
\hline National & 15.95 & & $4.90-51.85$ & $<0.001$ \\
\hline Export & 9.02 & & $2.20-36.91$ & 0.002 \\
\hline $\begin{array}{l}\text { Zone of sacrifice } \\
\text { (> slaughter zone) }\end{array}$ & 9.05 & & $2.96-27.63$ & $<0.000$ \\
\hline $\begin{array}{l}\text { Use of vehicle ( pigs and other } \\
\text { products) }\end{array}$ & 3.75 & & $1.55-9.08$ & 0.003 \\
\hline
\end{tabular}

In addition, factors related to the movement of pigs that played a role in the contamination of the truck by PEDV were: the national type slaughterhouse (OR 35.5, CI 95\%: 12.7-111.1), export type slaughterhouse (OR 33.1, CI 95\% : 10.0-109.63) and visits to animal feed mills (OR 13.56, IC 95\%: 4.1744.12). Table 4.

Table 4 Model 2: PEDV RT-PCR versus movement variables

$\begin{array}{llll}\text { Variable } & \text { Adjusted OR } & \text { CI 95\% } & \text { for adjusted OR p value }\end{array}$

\begin{tabular}{lccc}
\hline Slaughterhouse type & 35.58 & $12.71-111.15$ & $<0.000$ \\
National & 33.16 & $10.03-109.63$ & $<0.000$ \\
\hline Export & & & $<0$ \\
Visits to fairs (Yes) & 2.05 & $0.27-15.78$ & 0.49 \\
& & & $<0.000$
\end{tabular}

\section{Discussion}

In Colombia, PED was considered an exotic disease until March 2014, when the first case appeared in the Department of Cundinamarca, caused by an American pandemic strain (18). Between 2014 -2016 strains I and II of North American groups were identified and also the INDEL strain (low pathogenicity), so it is probable that there were multiple introductions of different genotypes into the country that were spread through the areas of greater porcine production, possibly through food, raw materials, contaminated fomites, or infected hogs (19). 
Biosecurity practices in farms started to be strengthened with the purpose of reducing the impact of PEDV in the country, as well as cleaning and disinfection measures of vehicles in the slaughterhouses. However, this study made evident that these measures at the beginning of the disease were not effective enough to decrease contamination of trucks with PEDV finding that $71.8 \%$ of the vehicles sampled entered the slaughterhouse positive with PEDV and 70.5\% exited contaminated. This differs from what occurred in the United States and Italy: In the case of US the $6.6 \%$ and the $4.3 \%$ was positive before and after unloading pigs respectively in the slaughterhouse, while in Italy the $14.1 \%$ was positive after unloading of the animals and the $46 \%$ remained positive after the cleaning and disinfection process of the trucks $(11,20)$. In Colombia, approximately two thirds of the trucks that went to slaughterhouses were contaminated with PEDV, observing a similarity in the rates of PEDV after going through a disinfection process, which suggests possible deficiencies in biosecurity both in the pigs transportation as in the slaughterhouses; however, we need additional studies to be able to affirm this and identify the strengths and weaknesses of the disinfection process. In regard to the above, the investigators consider that these results can be explained because the implementation of the biosecurity is voluntary and depends on the level of technification of the farms.

In the 2014 PEDV epidemic in the United States, the concentration points were an efficient source of contamination for the transport vehicles given that the incidence of contamination in slaughterhouse was directly proportional to the amount of PEDV contaminated trucks that arrived (11), besides not allowing the spread to large distances (21), which was consistent with our findings where places of concentration such as national and export type slaughterhouses and animal feed mills presented a greater possibility of contamination.

This is due to the fact that vehicles from different origins can arrive at these places, generating a greater flow of trucks, especially in the case of the zone of highest sacrifice where a large amount of the national and export type of slaughterhouses are concentrated; it is also important to consider that the majority of transporters that drive hogs to slaughterhouses do not stop during the journey. (22). For the case of the animal feed mills, the frequency of the visits is increased since the majority of the farms in the country do not produce their own feed for the hogs and it is stored only for short periods of time, increasing the frequency of the visits to the plant for procurement, and the flow of trucks; and is similar to what is reported by Sasaki et al. (23), who saw that an increase in the number of feed trucks that visit the farm increased the occurrence of PEDV by $16 \%$.

Unlike Lowe et al. (11) findings, who indicate that fairs are a source of PEDV contamination in the United States, that relationship was not observed in this study since, opposite to what happens in fairs in the United States, in the Colombian fairs, pigs of backyards or family premises of surrounding areas are generally sold, therefore, trucks that transport pigs to the slaughterhouses seldom visit fairs since it is not a profitable business and a large part of them are linked to commercial farms. Additionally, other factors that increase the probability of contamination with PEDV in Colombia are the non-exclusive use of vehicles to transport pigs, and that in many trucks the pig transport site is built with materials generally 
porous that don't allow an adequate process of cleaning and disinfection. These facts increase the problem.

In Colombia, the loading area of the majority of trucks for animal transportation is of irregular porous surfaces, seen in trucks of one of the zones of greater swine production in the country such as Antioquia, where the predominant materials are: aluminum floor $(46.8 \%)$, slats or plastic screen $(24.6 \%)$, wood $(14.8 \%)$ and metal (13.8\%); as well as iron separators (52.2\%), wood (35.5\%) and plastic (11.8\%) (22), which do not guarantee adequate cleaning and disinfection and thus can harbor virus (24), that together with PEDV survival capacity of up to 2 days at room temperatures $\left(\sim 25^{\circ} \mathrm{C}\right)$ in materials such as glass, stainless steel, plastic, and rubber $(13,15)$, enable the permanence of the virus on these surfaces.

Control measures such as segregation, hygiene and disinfection are important in order to limit spread of PEDV(11), where factors such as room temperature, structure, and porosity of materials contaminated with PEDV can play a role on their survival and thus have to be considered when developing biosecurity protocols $(13,14)$, which is consistent with the factors we identified to reduce contamination with PED: the location of the slaughterhouse in the zone of less sacrifice, general cleanliness of the vehicle, cleanliness of the cabin, use of disinfectant in cleaning processes, use of pressurized water during the washing of the farm, use of a back pump in the farm, and the exclusive use of the vehicle for the pigs transportation.

Despite the dissemination that PEDV had in the country, the impact of the disease was not as severe for the pig industry, that shows a growth of $5.3 \%$ and $11.6 \%$ of the amount of hogs sacrificed in 2014 and 2015 respectively (25), probably due to the fact that producers strengthened biosecurity in transportation, moving animals for sacrifice to local slaughterhouses to carry out dispatches of canals or pieces of deboned meat, avoiding points of concentration of animals and large distances.

Amongst the limitations of the study, we found that the information was obtained through surveys that did not consider variables related to the types of materials of the truck's housing, other information about biosecurity in farms and room temperature, which did not allow an in depth assessment; so these should be considered in future researches. Another limitation is that the PCR does not assess the viability of the virus; therefore, after the disinfecting process, is possible to detect viral RNA in the surfaces, without viable virus. That fact is very important to analyze the value of the differences between the entry and exit contamination rates. In this type of studies, it is not easy to participate, due to lack of interest of participating as a volunteer. To the date of the study there were not standardized surveys that allowed assessing attitudes and behaviors, which suggests building a measurement scale that can allow identifying biosecurity behaviors in the drivers and staff that works in transportation.

Similar to what happened in Italy, the results of this study suggest that the strengthening of cleaning and disinfection measures for vehicles under standardized protocols should become a common practice in the slaughterhouses; that, together with limiting the drivers from stepping down from the vehicles once inside the slaughterhouses, and reinforcing biosecurity practices in transportation, would reduce the 
dissemination of diseases through transportation trucks besides reinforcing training programs and raising awareness to both producers and drivers.

\section{Conclusion}

The high degree of mobilization of the trucks to points of concentration, failures in biosecurity and the survival characteristics of the virus, enabled the spread of PEVD throughout the entire national territory, turning it into an endemic disease in Colombia. However, the measures implemented by the drivers played a role in that the impact of the disease were less.

This work offers a general vision of the practices that were carried out in the country during 2014 at the beginning of the epidemic in Colombia and saw the need of standardizing and regulating biosecurity protocols for slaughterhouses, pig transportation and farms, and thus prevent entrance of infections and reduce the impact of diseases in the country.

\section{Methods}

This is a cross-sectional observational study that intended to find an association between pig transportation practices from the farms to the slaughterhouses, and the presence of PEDV in the trucks, by sampling trucks and applying a questionnaire to drivers.

\section{Sampling Design:}

A stratified sample was designed by proportional assignment in the 32 main slaughterhouses recorded by the National Institute for Food and Drug Surveillance - INVIMA[1] considering the following parameters: population 3.143 trucks transporting pigs that entered the slaughterhouse in 2014, 1\% PEDV prevalence, $95 \%$ confidence level, $30 \%$ percentage of expected loss, $1 \%$ of error, resulting in a sample size of 518 trucks. The gathering of samples was carried out during the second semester of 2014 during a period of a week in each one of the slaughterhouses. The samples were distributed over the week according to the order of arrival of the trucks. The sampling was done on the trucks at the point of entrance and the point of exit of the slaughterhouses, and the environmental samples were analyzed with RT-PCR.

\section{Sampling of trucks:}

Samples were taken at two different moments: one upon arrival, after the unloading of the animals in the slaughterhouse, and another sample after the disinfection of the trucks. The sample was a sweep of the internal surface of the truck using a sterile methylcellulose sponge $\left(3 \mathrm{M}{ }^{\circledR}\right)$, previously moistened in a saline or phosphate buffer. Pools of 10 points of the floor of the truck were taken, that corresponded to the area where the pigs are located, sampling in the shape of an " $X$ ", starting by the door and ending towards the bottom of the truck body considering that the dimension, structure, and materials of the trucks varies in the country. Subsequently, the pad was placed in a sterile bag and the liquid was recovered applying manual pressure. The liquid was transferred to a sterile $15 \mathrm{ml}$ Falcon tube, was 
stored at $4^{\circ} \mathrm{C}$ and was transported to the veterinary virology laboratory at the National University of Colombia in Bogota.

\section{Surveys to pig transporters:}

The truck drivers sampled in the slaughterhouses filled in a survey. They survey contains information on management and biosecurity practices used for transportation vehicles in slaughterhouses and farms and during transportation of animals. This information was used to classify the practices employed for the transportation of animals and to identify factors associated with contamination from PEDV during transport of animals. (The survey format is included in the supplementary material).

\section{Sample processing:}

Once in the laboratory, the samples were diluted 1:10 in phosphate-buffered saline in eppendorf tubes and centrifuged at $10,000 \mathrm{~g}$ for $10 \mathrm{~min}$ at $4^{\circ} \mathrm{C}$. The supernatants were transferred to other eppendorf tubes and RNA was extracted from $200 \mu \mathrm{L}$ of the sample using the RNAsy extraction kit (QIAGEN ${ }^{\circledR}$ ) following the manufacturer's instructions. Subsequently, cDNA synthesis was made using the High Capacity cDNA Reverse Transcription Kit (Applied Biosystems ${ }^{\circledR}$ ). For a reaction of 20 ul, 3.2 ul of water, 2 ul of Buffer RT, 0.8 ul of dNTPs, 2 ul of random primers, 1 ul of RNase inhibitor, 1 ul of RT and $10 \mathrm{ul}$ of RNA were added. he reverse transcription conditions were 1 cycle $25^{\circ} \mathrm{C}$ for $10 \mathrm{~min}$, one cycle at $37^{\circ} \mathrm{C}$ for 120 minutes and 1 cycle $85^{\circ} \mathrm{C}$ for 5 minutes. The RT-PCR reactions were performed on a C1000 Touch BIORAD-DNA thermocycler (Biorad; CA, USA) and the CDNA was stored at $-20^{\circ} \mathrm{C}$ for later use. All samples were quantified using a NanoDrop 2000 (Thermo Fisher Scientific®, Waltham, MA, USA).

For PEDV detection in samples, real-time PCR assays were performed to amplify segments of the $\mathrm{N}$ and $\mathrm{S}$ genes, following exactly the protocol kindly provided by the Veterinary Diagnostic Laboratory University of Minnesota. For the $\mathrm{N}$ gene the primers and probe were (PED-N-For 5'- GAATTCCCAAGGGCGAAAAT -3', PED-N-Rev 5'- TTTTCGACAAATTCCGCATCT -3' and PED-N 5'- FAM-CGTAGCAGCTTGCTTCGGACCCABHQ $-3^{\prime}$ ), generating an 87bp amplicon; while for the S gene (PED-S- For $5^{\prime}$ - ACGTCCCTTTACTTTCAATTCACA -3', PED-S-Rev 5' - TATACTTGGTACACACATCCAGAG-TCA -3', and PED-S 5 '- FAM-TGAGTTGATTACTGGCACGCCTAAACC - BHQ - 3'), generating a $111 \mathrm{bp}$ amplicon. In all cases reactions were performed in a total volume of $20 \mathrm{ul}$ containing $3.6 \mathrm{ul}$ of water, $10 \mathrm{ul} \mathrm{PCR}$ buffer, $0.3 \mathrm{ul}$ of Primer forward, $0.3 \mathrm{ul}$ of Primer reverse, $0.8 \mathrm{ul}$ of probe and $5 \mathrm{ul}$ of cDNA. The thermal profile of the real time PCR in both cases was initial denaturation at $95^{\circ} \mathrm{C}$ for $10 \mathrm{~min}$ followed by 42 divided into $95^{\circ} \mathrm{C}$ for $10 \mathrm{sec}, 60^{\circ} \mathrm{C}$ for $60 \mathrm{sec}$ and $72^{\circ} \mathrm{C}$ for $1 \mathrm{sec}$. The real-time PCR reactions were performed on real-time LightCycler 480 (Roche $\left.{ }^{\circledR}\right)$. Molecular grade water was used as a negative control for amplifications and the positive control was a synthetic PEDV sequence sent by the Veterinary Diagnostic LaboratoryUniversity of Minnesota, which contains both the $\mathrm{N}$ gene and the $\mathrm{S}$ gene on the same sequence. All samples found with a $\mathrm{Cp} \leq 35$ (greater than 40,2837 copies of $\mathrm{N} / \mathrm{mL}$ ) were considered positive and between 35 and 40 as suspect (less than 4,283 copies $\mathrm{N} / \mathrm{mL}$ ). The confirmation of positivity was given by the amplification of the $S$ gene under the criterion of a $\mathrm{Cp} \leq 35$ as positive (greater than 80,567 copies 
$\mathrm{S} / \mathrm{mL}$ ). The standardization of the real time PCR technique was developed by the Veterinary Laboratory of the National University of Colombia, Bogotá.

Statistical analysis:

We carried out the descriptive analysis of the variables through frequency distributions, central tendency measures, and dispersion. The prevalence of contamination from PEDV in trucks at the entrance and exit of the slaughterhouses was estimated, besides the characterization of the practices related to the transportation of pigs to the slaughterhouses.

To determine the association between the RT-PCR PEDV dependent variable at the entrance of the slaughterhouse and the independent variables, the association test of chi-square or the exact Fisher test was used and we estimated the magnitude of the association with an OR Cl of $95 \%$. The differences between the prevalence of PEDV at the entrance with the prevalence of PEDV at the exit of the slaughterhouse were compared using a McNemar test.

A multivariable logistic regression model was used to determine the variables that help explain the probability of contamination with PEDV and for this model the variables that were taken into account were those that were statistically significant in the previous analyses and showed epidemiological importance in the transmission of the virus. Consequently, the possible effects of interaction and confounding were studied. Finally, the model that best explained the event probability was selected. For the control of biases and errors, aspects such as sample type and sample size, clear inclusion and exclusion criteria, question writing, expert review and standardized training of interviewers were considered. The software used for the analyses was EPI INFO 7 and SPSS 22, with a license provided by Rosario University.

[1] These 32 slaughterhouses represent the $73 \%$ of the pigs slaughtered legally in the country . The slaughterhouses are classified as national, national -export and local, according to Decree 2270/2012 of the Ministry of Health, regulated by the National Institute for Food and Drug Surveillance - INVIMA. In the present study, the national-export slaughterhouses were called export-type slaughterhouses since they are authorized to export and to avoid confusion.

\section{Abbreviations}

INVIMA: National Drug and Food Surveillance Institute.

OR: Odds Ratio

PED: Porcine Epidemic Diarrhea

PEDV: Porcine Epidemic Diarrhea virus

Page $11 / 15$ 
RT-PCR: Reverse Transcriptase Polymerase Chain Reaction.

\section{Declarations}

\section{Ethics approval and consent to participate:}

This study was approved by the bioethics committee of the faculty of veterinary medicine of the National University of Colombia, did not have intervention measures in the pigs since the sampling was carried out in the pig's trucks at the point of entry and exit of the slaughterhouses. The objective of the study was explained verbally to the truckers from whom verbal consent was obtained to answer the survey and participated voluntarily.

\section{Consent for publication:}

Not applicable

\section{Availability of data and materials:}

The datasets used and analyzed during the current study are available from the corresponding author on reasonable request.

\section{Competing interests}

None of the authors of this paper has a financial or personal relationship with other people or organizations that could inappropriately influence or bias the content of the paper. The authors declare that they have no competing interests.

\section{Funding:}

The present study was realized with the support of CENIPORCINO (research and technology transfer center of the pig sector) and was financed with resources from the Colombian Association of Pig-farmers - Porkcolombia - National Fund for Pig-farming. The funding agency CENIPORCINO collaborated in the design of the study and the collection of information.

This manuscript was supported by the School of Medicine and Health Sciences, Universidad del Rosario, for English editing.

\section{Authors' contributions:}

PP and PC: Designed and implemented the research, analyzed the data and wrote the manuscript.

$\mathrm{GH}$ : Statistical consultant, analyzed the research data and participated in the preparation of the publication. 
CT: Methodological adviser, analyzed the research data and participated in the preparation of the publication.

CZ: Thematic adviser, conceptualized the study, designed and implemented the research and participated in the preparation of the publication.

All authors approved the final version of the manuscript for publication.

\section{Acknowledgements}

The authors express theirs thanks to the Colombian Association of Pig-farmers / National Fund for Pigfarming, CENIPORCINO, Veterinary Virology Laboratory of the National University of Colombia - Bogota, Universidad CES and Universidad del Rosario.

\section{References}

1. Lee S, Kim Y, Lee C. Isolation and characterization of a Korean porcine epidemic diarrhea virus strain KNU-141112. Virus Res. 2015;208:215-24.

2. Pan $Y$, Tian X, Li W, Zhou Q, Wang D, Bi Y, et al. Isolation and characterization of a variant porcine epidemic diarrhea virus in China. Virol J. 2012;9:195.

3. Shibata I, Tsuda T, Mori M, Ono M, Sueyoshi M, Uruno K. Isolation of porcine epidemic diarrhea virus in porcine cell cultures and experimental infection of pigs of different ages. Vet Microbiol. 2000;72(3-4):173-82.

4. Crawford K, Lager K, Miller L, Opriessnig T, Gerber P, Hesse R. Evaluation of porcine epidemic diarrhea virus transmission and the immune response in growing pigs. Vet Res. 2015;46:49.

5. Lee C. Porcine epidemic diarrhea virus: An emerging and re-emerging epizootic swine virus. Virol J. 2015;12(1):193.

6. Goyal SM. Environmental stability of PEDV (porcine epidemic diarrhea virus) - NPB \#13-215 [Internet]. Saint Paul, MN; 2014. Available from: https://www.pork.org/wpcontent/uploads/2015/12/13-215-GOYAL-UMN.pdf

7. Saif LJ y SK. Transmissible gastroenteritis and porcine respiratory coronavirus. In: Straw BE, Zimmerman JJ DS y T, editor. Diseases of Swine. 9th ed. lowa USA: Blackwell Publishing; 2006. p. 489-516.

8. Lee C. Porcine epidemic diarrhea virus: An emerging and re-emerging epizootic swine virus. Virol J. 2015;12(2015):1-16.

9. Dee S, Clement T, Schelkopf A, Nerem J, Knudsen D, Christopher-Hennings J, et al. An evaluation of contaminated complete feed as a vehicle for porcine epidemic diarrhea virus infection of naive pigs following consumption via natural feeding behavior: proof of concept. BMC Vet Res. 2014;10:176.

10. Geiger JO, Connor JF. Porcine Epidemic Diarrhea, Diagnosis and Elimination [Internet]. 2013. Available from: https://www.aasv.org/aasv website/Resources/Diseases/PED/13-05- 
29PEDWhitePaper.pdf

11. Lowe J, Gauger P, Harmon K, Zhang J, Connor J, Yeske P, et al. Role of transportation in spread of porcine epidemic diarrhea virus infection, United States. Emerg Infect Dis. 2014;20(5):872-4.

12. Aubry P, Thompson JL, Pasma T, Furness MC, Tataryn J. Weight of the evidence linking feed to an outbreak of porcine epidemic diarrhea in Canadian swine herds. J Swine Heal Prod. 2017;25(2):6972.

13. Kim Y, Krishna VD, Torremorell M, Goyal SM, Cheeran MCJ. Stability of porcine epidemic diarrhea virus on fomite materials at different temperatures. Vet Sci. 2018;5(1).

14. VanderWaal K, Perez A, Torremorrell M, Morrison RM, Craft M. Role of animal movement and indirect contact among farms in transmission of porcine epidemic diarrhea virus. Epidemics. 2018;24:67-75.

15. Torremorel Montse, Goyal Sagar M CM. Extent of contamination, quantification and survival of PEDV in fomites and effect of disinfectants on swine coronaviruses - NPB \#14-275 [Internet]. 2015. Available from: https://www.pork.org/wp-content/uploads/2015/12/14-275-TORREMORELLUofMN.pdf

16. Cima Greg. PED virus reinfecting U.S. herds. J Am Vet Med Assoc. 2014;245(2):166-7.

17. Stevenson GW, Hoang H, Schwartz KJ, Burrough ER, Sun D, Madson D, et al. Emergence of Porcine epidemic diarrhea virus in the United States: clinical signs, lesions, and viral genomic sequences. J Vet Diagn Invest. 2013 Sep 20;25(5):649-54.

18. Jarvis MC, Lam HC, Rovira A, Marthaler DG. Complete genome sequence of porcine epidemic diarrhea virus strain COL/Cundinamarca/2014 from Colombia. Genome Announc. 2016;4(2):42304.

19. Zambrano DC, Pineda P, Marthaler D, Diaz A, Rojas D, Calderon C RM. Diarrea Epidemica Porcina: seguimiento de la enfermedad en Colombia. Revista Porkcolombia. 2017;230:22-7.

20. Boniotti MB, Papetti A, Bertasio C, Giacomini E, Lazzaro M, Cerioli M, et al. Porcine Epidemic Diarrhoea Virus in Italy: Disease spread and the role of transportation. Transbound Emerg Dis. 2018;65(6):1935-42.

21. O'Dea EB, Snelson H, Bansal S. Using heterogeneity in the population structure of U.S. swine farms to compare transmission models for porcine epidemic diarrhoea. Vol. 6, Nature Scientific Reports. 2016.

22. Benavides MF. Caracterización del transporte y practicas de conducción en cerdos en pie dirigidos a plantas de beneficio en el Valle de Aburra [Internet]. Universidad CES; 2017. Available from: https://repository.ces.edu.co/bitstream/10946/4410/2/Caracterización Trasporte Cerdos.pdf

23. Sasaki Y, Alvarez J, Sekiguchi S, Sueyoshi M, Otake S, Perez A. Epidemiological factors associated to spread of porcine epidemic diarrhea in Japan. Prev Vet Med. 2016;123:161-7.

24. Bowman AS, Nolting JM, Nelson SW, Bliss N, Stull JW, Wang Q, et al. Effects of disinfection on the molecular detection of porcine epidemic diarrhea virus. Vet Microbiol. 2015;179(3-4):213-8.

25. Porkcolombia-FNP CA of pigs farmes. Proyects management reports [Internet]. Bogota D.C. Col; Available from: https://www.miporkcolombia.co/informes-de-gestion/ 


\section{Figures}

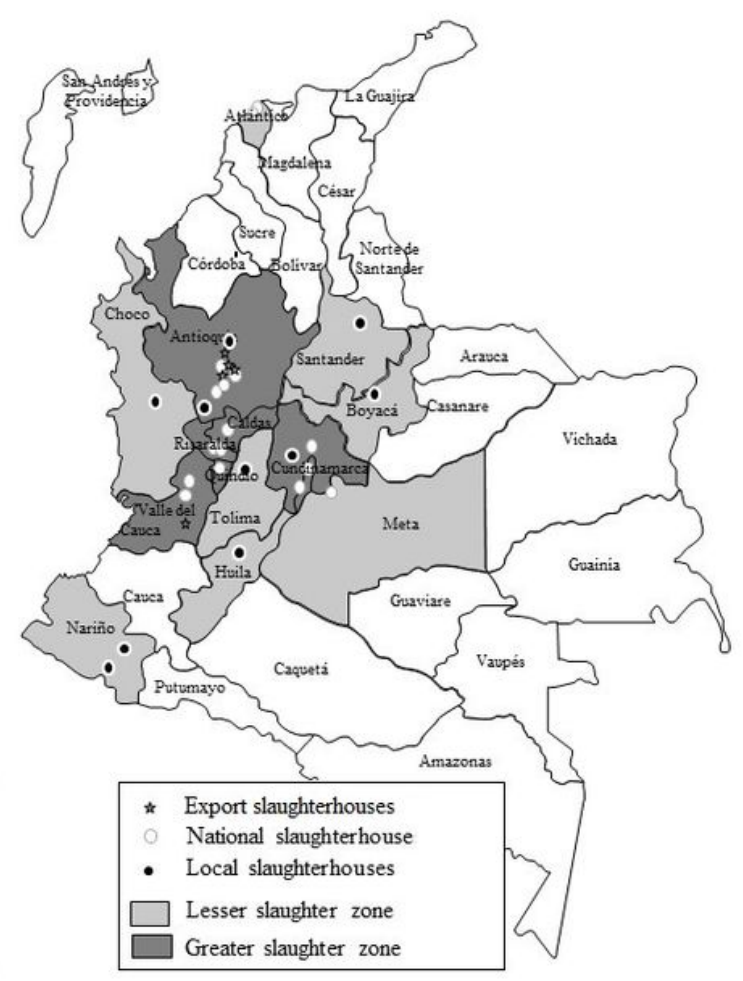

Figure 1

Geographical distribution of slaughterhouses in the country according to the type of slaughterhouse (local, national or export) and the slaughter area (area of greater or lesser slaughter)

\section{Supplementary Files}

This is a list of supplementary files associated with this preprint. Click to download.

- Materialsuplementariounivariado.xIsx

- Materialsuplementarioencuesta.pdf

- Supplementarymaterialunivariate.xlsx

- Table1.xlsx

- Table2.xlsx

- Table4.xlsx

- Table3.xlsx

- Supplementarymaterialquestionnaire.pdf 